\title{
TECHNOLOGY READINESS AND CUSTOMER SATISFACTION WITH TRAVEL TECHNOLOGIES: A CROSS-COUNTRY INVESTIGATION
}

\begin{abstract}
Technologies have dramatically transformed tourist experience. However, research has largely focused on traveler attitudes and technology adoption rather than their experience with travel technologies. Taking a cross-country perspective, this study examines the role of technology readiness (TR) as a personality trait in shaping travelers’ satisfaction with travel technologies, using airlines as a case study. Results of an online survey of travelers in Australia, China, and the U.S. revealed the moderating effects of the TR dimensions of optimism and innovativeness as well as country of residence on the relationships between perceived quality of technologyenabled services (TESs), satisfaction with TESs, overall satisfaction, and future behavior. These relationships were stronger among travelers with higher TR and in the American sample. The results suggest that tourism and hospitality service providers should incorporate measures of traveler TR and TESs’ performance into their customer-experience monitoring system.
\end{abstract}

Keywords: Travel technologies, tourist readiness, airlines, cross-country comparison 


\section{Introduction}

Technologies, such as the Internet and mobile technologies, are particularly prominent in the travel industry (Giebelhausen et al. 2014) and have become a major channel for travel commerce (Ert and Fleischer, forthcoming; Tussyadiah and Wang, forthcoming). Hotels, airlines and attractions are augmenting traditional face-to-face service strategies with technology-enabled service (TES) interactions. Businesses implement technologies (e.g., online booking and review sites) to aid travelers' decision marking and trip planning (Xiang et al. 2015). On-site, technologies (e.g., podcast and smartphone) enable effective problem solving for travelers and can offer effective means of interpretations, significantly enhancing learning outcomes, enjoyment, and experience (Kang and Gretzel 2012a and 2012b; Wang, Xiang, and Fesenmaier 2016). Technologies also assist with better engaging the new and existing (So, King, et al. 2016; So, King, and Sparks 2014), and technology-savvy generation of travelers (Kang and Gretzel 2012a and 2012b), as well as offer customers efficiency, convenience, and greater control (Buell, Campbell, and Frei 2010). However, research has highlighted the paradoxical nature of travelers' technology-related experiences, which not only provide benefits but can also create feelings of frustration, anxiety, stress, isolation, and chaos, resulting in dissatisfaction and leading to various coping strategies such as avoidance (Johnson, Bardhi, and Dunn 2008).

Tourist behavioral models recognize the critical influence of personal/trip characteristics (e.g., attitude and personality) and environment (i.e., physical and social entities of contact) (Lamsfus et al., forthcoming). Travelers' use of and satisfaction with technologies hinges on their technology readiness (TR), a personality trait defined as “ the propensity to embrace and use new technologies for accomplishing goals” (Parasuraman 2000, p. 308). TR is an important determinant or moderator of consumer attitudes toward and adoption of Technologies (e.g., 
Chen, Chen, and Chen 2009; Walczuch, Lemmink, and Streukens 2007). The context within which technologies are experienced is critical as it sets the basis for understanding travel behavior (Lamsfus et al. 2015). Given that the travel environment is increasingly digitized with tourists literally traveling in physical and virtual IT-supported networks (Lamsfus et al. 2015), the TR construct has never been more relevant to tourism research than it is now. This study is a cross-country investigation of traveler experience with TESs in the tourism consumption process. It uses consumer experience with airline TESs as a case study to evaluate a framework for understanding satisfaction with TESs, which includes the evaluation of TES quality, leading to satisfaction with TESs and the overall trip experience, and future behavioral intentions. The study's major contributions are 1) to conceptualize and examine the moderating role of traveler characteristic of TR in shaping customer satisfaction and 2) to consider TR's role in the framework of satisfaction in a cross-country sample including Australian, American, and Chinese travelers. The airline sector is chosen because of its particularly advanced TESs offerings, ranging from self-check-in facilities to onboard services such as entertainment systems and Wi-Fi access (Wang and Sparks 2014; Wang, So, and Sparks, forthcoming). Research also posits that service provision in many industries is affected by the introduction of Self-Service Technology, none more so than in the airline industry and these services significantly impact the majority of airline passengers (de Groot 2015), making TR a highly relevant concept.

The study addresses significant literature gaps related to TESs, satisfaction with TESs (Meuter et al. 2003; Makarem, Mudambi, and Podoshen 2009), and the subsequent post-service behaviors (Buell, Campbell, and Frei 2010). To date, TES-related research has concentrated largely on customer acceptance and adoption of these services (e.g., Lassar, Manolis, and Lassar 2005; Walczuch, Lemmink, and Streukens 2007) and the ways in which technologies shape 
aspects of tourist behaviors and experiences (e.g., Kang and Gretzel 2012a; Lamsfus et al. 2015; Kang and Gretzel 2012b; Tussyadiah and Zach 2012; Wang, Park, and Fesenmaier 2012; Wang, Xiang, and Fesenmaier 2016; Xiang, Magnini, and Fesenmaier 2015; Xiang et al. 2015). While an enhanced understanding of these aspects of TESs is critical, further insights into whether and why travelers feel satisfied with TES offerings is equally, if not more, important. The primary justification for focusing on satisfaction lies in its positive association with key consumer outcomes such as customer retention and loyalty, both online and offline (e.g., Lu, Wang, and Hayes 2012). Nevertheless, adequate service quality online is often lacking, calling for a better understanding of consumers' e-satisfaction and tech-satisfaction (Parasuraman, Zeithaml, and Malhotra 2005; Zeithaml, Parasuraman, and Malhotra 2002).

This study also responds to the need to incorporate personal characteristics beyond demographic factors in understanding travelers’ technology-assisted experience (Kang and Gretzel 2012b). Personality research provides useful insights as personality is particularly influential in predicting behavior overtime and across situations in relation to a wide range of human behaviors (Yoo and Gretzel 2011). Previous TR studies reside largely within the research adopting Technology Adoption Model (TAM) and related models; they are often in the context of information and communication technologies (e.g., Chen, Chen, and Chen 2009; Lin and Hsieh 2007). Limited TR research in tourism investigates customers' attitude toward rather than experience of TESs (e.g., Wang and Sparks 2014; Wang, So, and Sparks, forthcoming, considers only some aspects of TR (e.g., Kang and Gretzel 2012b), with little focus on TR's role in shaping tourist satisfaction. Investigators outside the tourism field proposes a direct impact of TR on satisfaction as a consumption outcome without considering the antecedents and outcomes of 
satisfaction (Chen 2011; Lin and Hsieh 2006 and 2007). This study departs from previous research by empirically verify TR's moderating role in the framework of tourism satisfaction.

Researchers question the assumption of uniform influence of personality traits across countries (Truong 2013; Tellis, Yin, and Bell 2009), and highlight the danger of overgeneralization of findings based on general technology acceptance and adoption models (Truong 2013). Contextual factors that shape technology related behavior vary from one country to another (Gretzel, Kang, and Lee 2008), highlighting the need for comparative studies of TR across countries and cultures (Parasuraman 2000). Limited TR research into the tourism domain (e.g., Lee, Castellanos, and Choi 2012; Wang, So, and Sparks, forthcoming; Wang and Sparks 2014) lacks the cross-country perspective and often examines data from a developed country (e.g., Australia). The generalizability of the findings remains unknown. This study collected data in Australia, China, and the U.S., providing a more global sample, enabling exploration of the model's applicability across tourists of varying cultural background, economic condition and technological environment. Theoretically, cross-country studies inform the subject of technology adoption, diffusion, and evaluation across markets. Practically, such studies are particularly meaningful for tourism businesses because of their global footprints and international consumer bases, assisting service providers and marketers who are facing the challenge of adapting to the specific needs of segments within the markets (Gretzel, Kang, and Lee 2008).

\section{Literature Review}

Service Quality, Tourist Satisfaction, and Post-Trip Behaviors

Service quality and satisfaction are separate constructs. Evaluation of service quality is largely cognitive, emphasizing effectiveness and efficiency. Studies on the quality of e-services and selfservice technologies assess attributes such as speed of delivery, ease of use, reliability, security, 
and control (Dabholkar 1996; Elliott, Meng, and Hall 2012; Zeithaml, Parasuraman, and Malhotra 2002). In contrast, satisfaction is the overall cognitive or affective response to product use (Oliver 1997). Superordinate to quality, it is a more emotional response to service encounters (Bowen and Clarke 2002). Researchers generally agree that cognitive evaluations of service quality precede emotional responses and that service quality is a strong predictor of satisfaction in TESs. Studies of hotel websites (Polites et al. 2012), online travel agencies (Tsang, Lai, and Law 2010), and e-service use (Chea and Luo 2008) validate this service quality-satisfaction link.

Satisfaction leads to favorable consumer outcomes of positive word-of-mouth and repurchase intention (Szymanski and Henard 2001) as satisfied consumers tell their relatives and friends, providing free advertisement and promotion. User satisfaction predicts e-loyalty (Anderson and Srinivasan 2003), continued IT use intention (Son and Han 2011; Thong, Hong, and Tam 2006), website re-visit, WOM, repeat purchase (Gounaris, Dimitriadis, and Stathakopoulos 2010), continuance, complaint, and recommendation with regard to various eservices (Chea and Luo 2008). A study of hotel websites finds that e-satisfaction not only significantly affects e-loyalty, but also mediates the influence of positive website experience on e-loyalty (Polites et al. 2012). Evidence shows that satisfaction is formed on the basis of evaluation of service quality against expectation, which leads to future intentions, and this sequence of events applies to various services sectors such as hotels (Beatson, Coote, and Rudd 2006), banking (Ganguli and Roy 2011), and e-shopping (Gounaris, Dimitriadis, and Stathakopoulos 2010).

Tech-satisfaction presents a key challenge for researchers. Satisfaction with a website may stem from the characteristics of the website and its associated vendors, products, or services. A customer may be loyal to the website itself or to a vendor operating on the website 
(Polites et al. 2012). Regarding travel experiences, TESs are often peripheral rather than core features, although travelers’ experience with TESs before, during, and after the trip would contribute to their overall satisfaction. However, since their loyalty is more likely to form toward the service provider (e.g., hotel/airline) than its technological service features, it is necessary to differentiate satisfaction with technologies from satisfaction with the overall experience.

This study proposed the below model, conceptualizing the role of TR (Figure 1). The model posits:

Hypothesis 1: TES quality is positively related to satisfaction with TESs.

Hypothesis 2: Satisfaction with TESs is positively related to overall satisfaction.

Hypothesis 3: Overall satisfaction is positively related to future behavioral intentions.

Figure 1

\section{Moderating Effect of Travelers' TR}

The strength of relationships between constructs in Figure 1 varies under different conditions; research needs to explore factors that may moderate these relationships (Anderson and Srinivasan 2003). Travelers have different levels of tolerance in service evaluation, and travelers' characteristics affect their evaluation of services and technologies (Mattila and Mount 2003), suggesting a moderating effect of travelers' characteristics. Regarding TESs, travelers' perceptions of the benefits such services can offer, travelers' own capabilities, and their orientation to technologies are significant drivers of behaviors toward technology-assisted channels (Buell, Campbell, and Frei 2010; Wang and Sparks 2014; Meuter et al. 2003). In particular, consumers' individual-level factors such as personality traits moderate the relationship between e-satisfaction and e-loyalty (Anderson and Srinivasan 2003). 
TR is a personality trait, measuring one's orientation to technologies. The limited research investigating how TR affects satisfaction conceptualizes TR as a direct influencer of satisfaction (Lin and Hsieh 2006 and 2007; Mattila and Mount 2003), and occurred in a context where technology plays the main role in the product offering, such as an mobile services (Chen, Liu, and Lin 2013) and an electronic book reader (Ferreira, da Rocha, and da Silva 2014). Our study differs significantly from previous research since TESs are more peripheral than core product features in a travel experience. TR is thus unlikely to directly influence a traveler's overall satisfaction with the trip. Further, our focus is on satisfaction's relationships with its key antecedent and outcome rather than on satisfaction itself. Therefore TR is conceptualized as a moderator of the relationships between the constructs in Figure 1.

TR asserts influence through its impact on the perceived importance of TESs (Wang, So, and Sparks, forthcoming). A consumer's overall TR establishes a frame within which he/she values travel TESs (Wang and Sparks 2014). High-TR customers perceive technologies to be more useful (Walczuch, Lemmink, and Streukens 2007) and regard the technology-related aspect of travel experience as more important and weigh these aspects more heavily in evaluating the experience (Liljander et al. 2006; Wang and Sparks 2014). The perceived importance of a service exerts a moderating effect on the relationships between satisfaction, its antecedents and outcomes, and high-importance purchases have a stronger relationship between perceived service performance and satisfaction than do low-importance purchases (Tam 2011). Since low-TR customers do not highly value technology-related aspects, a positive or negative experience with technologies does not carry as much weight in their overall service evaluation. Compared to lowTR customers, high-TR customers are more comfortable with new technologies and have more prior experience with technologies, and consequently are less likely to encounter problems. They 
are also less likely to find technical difficulties intimidating and are more prone to continue to use technologies despite problems (Zeithaml, Parasuraman, and Malhotra 2002). Therefore, a traveler's TR may influence how complex he/she perceives a TES to be. Further, the psychological process and underlying dimensions of satisfaction may vary depending on the complexity of the consumption experience (Oliver 1997), and the level of service task complexity changes the magnitude of the effect of service process modularization on customer likelihood to try a new service (Tuunanen and Cassab 2011).

Further, TR influences travelers' beliefs, perceptions and expectations about technologies, based upon which travelers evaluate their technology-related experiences (Chung, Han, and Joun 2015). A meta-review of customer satisfaction literature concludes that comparison standard may be a potential moderator of customer satisfaction (Szymanski and Henard 2001). High-TR customers, because of their greater knowledge of technologies, are more demanding and have higher evaluative standards (Zeithaml, Parasuraman, and Malhotra 2002). TR therefore moderates the relationships between constructs in Figure 1, with the link likely to be stronger for high-TR travelers than low-TR travelers.

TR is a multi-dimensional construct that captures both the positive (i.e., optimism and innovativeness) and negative (i.e., discomfort and insecurity) mental readiness for technological innovations (Parasuraman 2000). Optimism refers to a positive view of technology and the belief that technology can offer customers increased control, flexibility, and efficiency in life and work (Parasuraman 2000). This perception of control plays a significant role in forming satisfaction with self-service technology (Johnson, Bardhi, and Dunn 2008). Optimistic people value TESs more (Wang, So, and Sparks, forthcoming), have higher trust in new technologies, and perceive the functionality of new technologies more positively (Lu, Wang, and Hayes 2012; Walczuch, 
Lemmink, and Streukens 2007). Optimism is positively associated with customers’ perceived ease of use and usefulness of technology-enabled financial services (Walczuch, Lemmink, and Streukens 2007), which increases customer satisfaction (e.g., (Thong, Hong, and Tam 2006). Innovativeness represents a customer's tendency to be a pioneer and thought leader in adapting to new technologies (Parasuraman 2000). Innovative customers are curious about new technologies and perceive themselves as highly competent in using new technologies and in handling uncertainties technologies present. They perceive the functionality of a new technology more positively (Lu, Wang, and Hayes 2012). The more an individual embraces innovative technologies, the more likely he/she would consider TESs to be useful (Walczuch, Lemmink, and Streukens 2007). Affecting performance expectancy for technology-assisted experience, innovativeness positively relates to museum visitors’ perceived impact of technology on consumption experience and the subsequent revisiting behavior through enhancing one's affinity with technology (Kang and Gretzel 2012b).

Airlines implement technological innovations to achieve reduced costs, greater capacity, faster speed, better management of security, and product flexibility (International Air Transport Association 2011; Kim, Park, and Morrison 2008). These goals are consistent with high-TR travelers’ goals to be seen as a pioneer in technologies. A stronger relationship is hence expected between service quality, satisfaction, and future behavior among optimistic and innovative travelers, leading to the following hypotheses:

Hypothesis 4: Optimism moderates the proposed set of relationships in Figure 1.

Hypothesis 5: Innovativeness moderates the proposed set of relationships in Figure 1.

Discomfort is “a perceived lack of control over technology and a feeling of being overwhelmed by it," while insecurity is defined as “distrust of technology and skepticism about 
its ability to work properly” (Parasuraman 2000, p. 311). Psychological discomfort is a key process that mediates the interactive effect of employee rapport behavior and technology use on service evaluation (Giebelhausen et al. 2014). Travelers who score high on discomfort and insecurity perceive operating TESs to be complex, and tend to be overwhelmed by technologies and feel a strong lack of control over their ability to handle uncertainties, resulting in an overestimation of technology's complexity. Those who feel insecure about technologies also experience higher level of anxiety when using new technologies and are skeptical about technology's usefulness (Lu, Wang, and Hayes 2012).

Discomfort and insecurity can lead to distrust of new technologies as well as low perceived functionality and usefulness (Lu, Wang, and Hayes 2012), affecting the relationships in Figure 1. While trust in technology increases satisfaction with TESs (Johnson, Bardhi, and Dunn 2008), some researchers assert that trust is a mediator or moderator rather than a direct predictor of satisfaction (e.g., Morgan and Hunt 1994; Polites et al. 2012; Lee and Wu 2011). Similarly, perceived usefulness and trust positively moderate the relationships between e-service quality, perceived value, and service satisfaction regarding airline websites (Lee and Wu 2011). Trust also affects the relationship between quality of online banking attributes (e.g., control, efficiency) and customer satisfaction (Johnson, Bardhi, and Dunn 2008). In addition, customers who feel anxious about technologies are less likely to have a positive experience with technologies even when technologies work well (Meuter et al. 2003). The following hypotheses were therefore proposed:

Hypothesis 6: Discomfort moderates the proposed set of relationships in Figure 1. Hypothesis 7: Insecurity moderates the proposed set of relationships in Figure 1. 


\section{Moderating Effect of Country of Residence}

Travelers’ cultural background affects their service expectations (Donthu and Yoo 1998) and technology acceptance (Meng, Elliott, and Hall 2009). Differences in uncertainty avoidance, masculinity/femininity, and power distance moderate the relationships in the widely accepted technology acceptance model (Srite and Karahanna 2006). Cultural differences also affect the effectiveness of technology transfer indirectly through an interaction with the nature of the technology being transferred (Lin and Berg 2001). A study comparing Korean and American customers' use of technology finds that culture moderates the relationships between expectancy, behavioral intention, and use behavior with these relationships being weaker in the Korean sample, which represents a culture with higher power distance, collectivism, and uncertainty avoidance and lower masculinity (Im, Hong, and Kang 2011). Similarly, collectivism and group orientation reduce the strength of relationships between perceived quality, satisfaction, and intention, because consumers with these cultural characteristics evaluate their service experience on the basis of group norms rather than individuals’ own standards (Spreng and Chiou 2002). The following hypothesis was proposed.

Hypothesis 8: Country of residence moderates the proposed set of relationships in Figure 1.

This study operationalized the testing of country of residence's moderating effect through a cross-national study involving Australian, Chinese, and American consumers. Australia is where research design was developed, serving as the initial testing ground for the research instrument. China and U.S. were chosen as they differ in terms of political governance, economic and technological development, as well as cultural values such as risk avoidance, group orientation, and trust (e.g., Hofstede and Hofstede 2001; Spreng and Chiou 2002). American consumers behave differently from their Chinese counterparts in relation to their use of 
technologies (Chu and Choi 2011). Chinese are less optimistic about technologies' ability to offer greater functionality and control over their life compared to the Americans (Meng, Elliott, and Hall 2009). Therefore, Chinese may be less likely to embrace new TESs. Practically, China and the U.S. are the world's top two tourism spenders in 2014 (UNWTO 2015), representing the largest consumer markets in the East and West, as well as tourism's largest traditional and emerging markets. Figure 2 summarizes the complete conceptual framework and proposed hypotheses.

Figure 2

\section{Methods}

This study utilized the airline sector as a case study and adopted a quantitative approach that included an online survey administered in Australia, China, and the U.S.

\section{Survey Instrument and Measures}

The instrument was developed based on academic literature and industry consultation to collect information on respondents' perceived quality of and satisfaction with airline TESs, satisfaction with the overall flight experience, future behavioral intentions, and TR, as well as social demographics and trip-related characteristics.

TES quality scale. The service quality scale measures perceived quality of service concerning TES offerings. A list of TESs, derived from academic literature, industry reports, travel websites, and blogs, was sent to top managers in the airline industry in Oceania. Using feedback of top managers of four major airlines, we revised the list, retaining 35 TES items.

Participants were instructed to evaluate TESs on the basis of their most recent flight experience in responding to the scale. As a traveler is unlikely to have used all 35 TESs, 
participants responded to this section in two steps: (1) participants indicated which of the TESs they had used, and (2) for those TESs they had used, they rated the quality of each relative to their expectation on a 7-point scale $(1=$ much worse than expected to $7=$ much better than expected).

Satisfaction scale. The survey used two scales, one measuring satisfaction with TESs and the other measuring satisfaction with the overall flight experience. Participants were instructed that the flight experience includes the actual flight and all associated experiences such as booking, check-in, and the baggage collection. Following (Anderson, Fornell, and Mazvancheryl 2004; Lin and Hsieh 2007), the three-item American Customer Satisfaction Index (ACSI) was used to measure travelers' satisfaction with airline TESs, with the wording modified to reflect the study context. The three items ask whether the TESs were generally satisfying, exceeded expectation, and were close to one's ideal. Participants indicated their responses on a 7-point Likert-type scale $(1=$ strongly disagree to 7 = strongly agree). Participants' satisfaction with the overall flight experience was also measured using the ACSI on a 7-point Likert-type scale, with modification in wording to reflect the overall flight experience.

Future behavioral intentions. The three-item instrument measures participants' post-flight behaviors, including future purchase, word-of-mouth advertising, and willingness to pay a premium price. These items reflect established important aspects of customer loyalty and future behavior toward a service provider (e.g., Ganguli and Roy 2011; Gounaris, Dimitriadis, and Stathakopoulos 2010).

TR scale. This study used the full 36-item TR Index, with permission for academic use from the copyright owners Parasuraman and Rockbridge Associates, Inc. (see Parasuraman 2000, for full 
scale). Participants indicated the extent to which they agreed or disagreed with each of the 36 items on a 7-point Likert-type scale ( 1 = strongly disagree and 7 = strongly agree).

\section{Pre-test and Pilot Test}

The questionnaire was hosted on a reputable website for research surveys. It was pre-tested with a convenience sample of 73 university faculty members and research students, and then pilottested with 161 participants with the assistance of a marketing list company. These tests identified potential issues in survey flow, readability, and logistics, and served as validity checks of construct measures, based on which the questionnaire was finalized. The questionnaire was translated into simplified Chinese by an accredited translator, then checked by three tourism scholars whose native language is Mandarin. A pre-test with a convenience sample of 30 faculty members and research students in a Chinese university was also conducted. Based on the pretest, the research team was satisfied with the comparative nature of the survey.

\section{Survey Procedures and Participants}

Access to potential respondents in Australia was obtained through a reputable marketing research firm and a sample was drawn from the company's privacy-compliant online consumer panel, a source of a pre-existing sampling frame consisting of more than 500,000 active members, providing a reasonable representation of the Australian population. A purposive sampling approach was taken where to be eligible to participate in this study, individuals must be over 18 years of age and had taken a flight in the past 12 months. A quota sampling approach was implemented to obtain a balance across genders, age groups and the different Australian states and territories. Items measuring TR, service quality, satisfaction, and future behavior were randomized to remove any systematic order effects. Access to potential participants in the U.S. was obtained in a similar manner through a U.S. based consumer panel provider. 
Owing to a lack of comparable consumer panel services in China, a different approach was used combing convenience and snowballing sampling strategies. A Chinese researcher assisted data collection. Postgraduate students were recruited to distribute the questionnaire online and sent email invitations to potential participants through popular social media sites such as Tencent Weibo, Sina Weibo, and QQ (an instant messaging software service offering a variety of services including micro blogging) and online communities of major Chinese airlines (e.g., Air China and China Southern Airlines) to elicit voluntary participation. Potential participants were encouraged to forward the survey link to friends who qualified for the study. Participants were offered the chance to enter a drawing to win one of 50 telecommunication cards each worth approximately AU\$20.

\section{Results}

A total of 1,407 usable surveys were completed, with 558 from the U.S., 509 from China, and 340 from Australia. Female respondents accounted for 50.8\% of the overall sample. Approximately 33.2\% of the respondents were under 30 years old, $40.1 \%$ were between 30 and 50, and $26.6 \%$ were over 50 . About $22.9 \%$ of the respondents held a postgraduate degree, $41.6 \%$ had university degrees, $13.9 \%$ held a certificate or diploma, $6 \%$ had trade qualifications, $11.6 \%$ were high-school qualified, 1.9\% had completed elementary school, and 2.1\% had other forms of education. To evaluate non-response bias for each sample, early and late respondents were compared on the demographic variables and the scale measures (Armstrong and Overton 1977). The results showed no significant differences between early (first 10\%) and late (last 10\%) respondents in terms of respondent characteristics and the measured items.

\section{Preliminary Analysis}


Examination of the skewness and kurtosis statistics of individual scale items showed that the data were not normally distributed. Then EFA was performed to assess measurement items within each scale to check uni-dimensionality, factor structure, and strength of factor loadings (i.e., loadings should exceed .50) (Gerbing and Anderson 1988). We used reliability analysis to examine the internal consistency of the scales via Cronbach's alpha, with values above .70 deemed to be appropriate (Nunnally 1978). Under these criteria several items were deleted, including one innovativeness item, one optimism item, three insecurity items, and one discomfort item. The retained scale items for each of the TR dimensions were used to compute composite variables for the subsequent test for moderation. Table 1 presents the mean scores for constructs.

Table 1

\section{Partial Least Squares Path Modeling}

The PLS approach to structural equation models, also known as PLS path modeling (PLS-PM) or PLS structural equation modeling (PLS-SEM), is a component-based estimation procedure that differs from the covariance-based LISREL-type approach, which has a primary goal of theory testing and confirmation (Hair et al. 2013). In contrast, PLS-PM explains the residual variance of the latent variables, and therefore its goal is predicting key target constructs (Fornell and Bookstein 1982; Hair et al. 2013). Unlike the covariance-based approach used in AMOS and LISREAL, PLS-PM analysis does not rely on the assumption of data normality and does not require as large a sample as other causal modeling techniques (Arnett, Laverie, and Meiers 2003; do Valle and Assaker, forthcoming). 
As this study aims to evaluate a set of predictive relationships and how the dimensions of TR and country affect these relationships, PLS-PM was the most appropriate analytical technique to examine the data. Furthermore, as the preliminary analysis results indicated that several items were not normally distributed, the use of PLS-PM was selected as the analytical technique for this study. The software package employed was XLSTAT.

\section{Measurement Model}

The analysis first assessed the measurement model through the validity and reliability of the construct measures. Convergent validity was evaluated through the strength and significance of the loadings, the average variance extracted (AVE), and the reliability estimates (Bagozzi and Heatherton 1994). As Table 2 shows, all loadings were satisfactory (> .70) (Gerbing and Anderson 1988) with one exception, which was slightly below the acceptable level of .70. However, the bootstrap critical ratios indicate that all indicators are statistically significant $(p<$ .001). Furthermore, all AVEs were greater than .50, exceeding the suggested threshold (Fornell and Larcker 1981). Taken together, the results provide strong evidence for the convergent validity.

\section{Insert Table 2}

Discriminant validity across the measured constructs was assessed by two methods (Hair et al. 2013). First, the item cross-loadings of the indicators were examined (Hair, Ringle, and Sarstedt 2011). Results showed that no items cross-loaded higher on another construct than they did on their own construct, supporting discriminant validity (Hair et al. 2013). Second, the square root of the AVE of the constructs was greater than the inter-correlations between constructs in 
each case, thus providing evidence of discriminant validity (Fornell and Larcker 1981; Chin 1998).

Construct reliability was assessed via internal consistency and indicator reliability (Hair et al. 2013). Internal consistency was evaluated with Dillon-Goldstein’s rho, which does not assume parallelity of the manifest variables as Cronbach's alpha does. All factors achieved satisfactory reliability (> .70) (Hair et al. 2006; Nunnally and Bernstein 1994), with DillonGoldstein’s rho values ranging from .88 to .93 (see Table 2). The results demonstrate that, overall, the scales were valid and reliable measures of their respective constructs.

\section{Structural Model}

The structural model was evaluated through a systematic examination of indices including $\mathrm{R}^{2}$, average variance accounted for (AVA), path coefficients between the exogenous and endogenous, and bootstrap critical ratios. As the primary objective of PLS-PM is prediction, the goodness of a theoretical model is established by the strength of each structural path and the combined predictiveness (Duarte and Raposo 2010). Given that the individual $\mathrm{R}^{2} \mathrm{~s}$ are greater than the recommended level of .10 (Falk and Miller 1992), the paths’ significance associated with these variables was examined. The analysis controlled for respondents' age group, gender, and educational level and all these variables were included as categorical control variables (Hair et al. 2013). The structural model results based on the overall sample data $(\mathrm{n}=1407)$ suggest that all paths coefficients were significant as the bootstrap critical ratios were greater than \pm 1.96 . Thus, Hypotheses 1, 2, and 3 were supported. Furthermore, a model has predictive power if the AVA is above $.10 . \mathrm{R}^{2} \mathrm{~s}$ for satisfaction with TESs, overall satisfaction, and future behavior were $.158, .654$, and .710, respectively, resulting in an AVA of .507 for this model (exceeding the cutoff of .10), thus indicating the predictive power of the individual paths and structural model. To 
show the predictive power of each endogenous variable included in the model, we also provide the variance due to path. Table 3 shows the results.

Table 3

\section{Test for Moderating Effects of TR Dimensions}

To examine the moderating effects of TR dimensions, a widely adopted median split method was used, dividing the overall sample into subgroups (e.g., high innovativeness vs. low innovativeness, high optimism vs. low optimism) (Henseler and Fassott 2010). Differences in the model parameters between the different data groups are interpreted as moderating effects. While such an analysis has often been conducted by examining path differences using a $t$-test based on the pooled standard errors obtained via a re-sampling procedure such as bootstrapping (Vinzi, Trinchera, and Amato 2010), problems can occur if a normal population or similar sample size is assumed (Chin and Dibbern 2010). The permutation-based procedure provides an alternative distribution-free approach based on an approximate randomization test, where a subset of all possible data permutations between sample groups is made (Vinzi, Trinchera, and Amato 2010). Having examined measurement invariance, using this approach, multi-group analyses were conducted to examine the differences in path coefficients (Hypotheses 4-8).

Table 4 shows that the links between satisfaction with TESs and overall satisfaction (difference $=.16, p<.01$ ) and between overall satisfaction and future behavioral intentions (difference $=.07, p<.01$ ) are significantly stronger for the high optimism group than for the low optimism group. However, the difference for the relationship between perceived TESs quality and satisfaction with TESs is not significant. Therefore, the results provide partial support for Hypothesis 4. Similarly, as Table 5 indicates, in the structural model for the high innovativeness group, the path coefficients from satisfaction with TESs to overall satisfaction (difference $=.14$, 
$p<.01$ ) and overall satisfaction to future behavioral intentions (difference $=.07, p<.01$ ) are significantly stronger than the corresponding path in the structural model for the low innovativeness group. The directional relationship between perceived quality of TESs and satisfaction with TESs is not significantly different between the two groups. Thus, the results partially support Hypothesis 5. Furthermore, as no significant differences were found in the three path coefficients between the high insecurity and low insecurity groups and between the high discomfort and low discomfort groups, Hypotheses 6 and 7 were not supported.

\section{Tables 4 and 5}

\section{Test for Moderating Effect of Country of Residence}

To test Hypothesis 8, a multi-group analysis was conducted to examine path differences across the three sampled country groups. As Table 6 indicates, the path from satisfaction with TESs to overall satisfaction (Hypothesis 2) is significantly stronger in the Chinese group than in the U.S. group (difference $=.05, p<.05$ ). While it was noted that the absolute path difference between China and Australia is greater than that between China and the U.S. (difference $=.06$ ), the latter was found insignificant in the moderating analysis based on the permutation method owing to the larger standard error of the path in the Australian sample. In contrast, the path from overall satisfaction to future behavioral intentions (Hypothesis 3) is significantly stronger in the U.S. group than in the Chinese group (difference $=.08, p<.01$ ). The results partially support Hypothesis 8.

Table 6 


\section{Discussion and Conclusions}

This study advances understanding of travelers' experience with technologies by proposing a conceptual model that incorporates travelers' TR into the existing framework of tourist satisfaction. Key findings include confirmation that travelers' perceived quality of airline TESs is positively associated with their satisfaction with TESs, which affects their overall satisfaction and post-consumption behavioral intention toward the airline (Hypotheses 1, 2, and 3). Partially confirming Hypotheses 4 and 5, the results suggest that optimism and innovation positively moderate the relationship between satisfaction with TES and overall satisfaction, as well as that between overall satisfaction and future behavior, but not the quality-satisfaction relationship. More optimistic and innovative travelers weigh TES offerings as more important in service consumption than those less optimistic and innovative about technologies (Wang, So, and Sparks, forthcoming), as reflected in air travelers' evaluation of their overall experience as well as future behaviors as measured by future purchase intention and WOM behaviors in this study. The two dimensions' lack of influence on the effect of TES quality on satisfaction may suggest that personal orientation to technology does not influence how a traveler evaluates technologyenabled service quality. A poor experience resulting from technical failure or non-response to email inquiry is likely to result in low satisfaction regardless of travelers' attitude. This result may also be related to the utilitarian goals of convenience, flexibility, and efficiency that many TESs meet for both travelers and airlines. As the evaluation of a service tends to be more objective and based on functional attributes of the service, it may be less subject to the influences of attitude and emotion.

This study provides no support for a moderating effect of discomfort and insecurity (Hypotheses 6 and 7). Being hospitality service providers, airlines designed TESs in ways that 
minimize anxiety and optimize usability (Wang and Sparks 2014). Onsite customer service support is often available at the airport or onboard, which eases customer anxiety. As such, discomfort and insecurity may be less relevant to hospitality TESs than they are to pure technological innovations. Further, customers' increasing familiarity with e-commerce environment may have resulted in a belief that major security issues have been addressed, diminishing the effect of the inhibitors of TR (Chen, Chen, and Chen 2009).

Our results also suggest a varying strength of relationship between key constructs in Figure 1 among travelers from the three countries, partially confirming Hypothesis 8 . The relationship between overall satisfaction and future behavior is stronger in the U.S. sample than in the Chinese sample, possibly because of Chinese travelers' conservative nature and cautiousness about new technologies. They are less optimistic about technologies ability to offer greater functionality compared to the Americans (Meng, Elliott, and Hall 2009). A cross-cultural study of the U.S. and China revealed significant differences in eWOM behaviors in terms of opinion-giving and seeking and information pass-along behavior (Chu and Choi 2011). The authors attributed these differences to the varying cultural orientations (i.e., individualism vs. collectivism) and social relationships (i.e., social capital, tie strength, trust, and interpersonal influence) in the two countries (Chu and Choi 2011). Our finding is also consistent with Im, Hong, and Kang's (2011) suggestion that the strength of relationship between performance expectancy and intention is weaker in Eastern cultures. However, the relationship strength between satisfaction with TES and overall satisfaction is stronger in the Chinese sample. Availability of self-service technologies is generally lower in China than in the US (Westjohn et al. 2009) and research presents evidence that customers of Chinese origin differ from Western travelers in their preferences and expectations of services (e.g., Donthu and Yoo 1998; Lu, Choi, 
and Tseng 2011; So, Liu, et al. 2016). Therefore, Chinese travelers may differ from Americans in the aspects of TESs they value, resulting in greater weighting of TESs in the evaluation of overall satisfaction and possibly explaining the stronger relationship between satisfaction with TES and overall satisfaction in the Chinese sample than in the American sample. Additional research is needed to fully delineate the underlying causes of the varying strength of relationships between the constructs in Figure 1.

\section{Theoretical and Practical Contributions}

Among the first to place TR in a broader framework of satisfaction related to technological aspects of tourism services, this study makes several theoretical contributions. Although the relationships among satisfaction and its antecedents and outcomes have previously been established, these relationships are likely to be affected by contextual factors such as types of services, consumer characteristics, and business environment. Using airlines as a case study, this study evaluates the service quality-tourism satisfaction relationship on technology-assisted service platforms. The study differs from much of the existing research on TES, which concentrates on customers' attitudes toward technology and their subsequent adoption behavior (e.g., Elliott, Meng, and Hall 2012; Ferreira, da Rocha, and da Silva 2014). While understanding adoption behavior is critical, the long-term sustainability of business requires continuous use of technology beyond initial adoption (Son and Han 2011). This study contributes to the scarce literature on post-adoption behavior related to TESs.

The study clarifies TR's role in shaping tourism satisfaction, as little research has examined the impact of TR on consumer behavior (Lin and Hsieh 2007) and post-adoption behavior (Son and Han 2011), adding to the limited body of literature on personality traits' influence in technology assisted experiences. This study conceptualizes and tests TR as a 
moderator of the satisfaction's relationships with its antecedents and outcome within tourism consumption. By focusing on a series steps leading up to satisfaction and the consequent behavioral outcomes, this study delineates how satisfaction may be conditioned on TR in different phases of a consumption experience, providing greater insight into ways of enhancing travelers' consumption experience. This constitutes a high level of theoretical contribution by adding a new "what" (i.e., a construct) to an existing theory in order to describe "how" the relationships unfolds and "when," or "for whom” the relationships are likely to be manifested (Whetten 1989). Future research concerning travel technologies should consider TR as a moderating variable. Further, this investigation adds to the limited research on cross-country comparison of tourist experiences in general and with technology in particular. The study verified the satisfaction framework across the U.S., Australian, and Chinese samples and highlighted the need to consider traveler cultural background in researching travel technologies.

Practically, the findings suggest that across markets, TESs have become important features of tourism services that significantly affect traveler satisfaction with the overall tourism experience. Ensuring a positive experience for travelers is thus critically important. To identify strengths and weaknesses related to TES offerings, businesses should develop measures of TES quality and incorporate TES-related satisfaction indicators into the system monitoring overall customer experience. Further, TR is important to consider in service offering, as it not only influences the adoption of travel technologies but also shapes travelers' satisfaction and postadoption behavior. Businesses should recognize travelers’ TR as an influential factor in TESrelated service design and implementation. Although TR is not a directly observable customer characteristic, high-TR travelers can be distinguished from low-TR travelers by their use of TESs. For instance, as highly innovative customers are often the first to adopt a newly offered 
service, airlines and hotels could maintain a database recording customers’ interactions with TESs so as to predict their reactions to new offerings and tailor marketing materials accordingly. Customer surveys incorporating TR measures might also be conducted with a sample drawn from the database to determine the TR of various market segments.

In low-TR markets, businesses introducing a new TES can emphasize orienting travelers toward the TES through trial, briefing, on-site demonstration, and online video, to display its benefits. Customer testimony should be highlighted to ease anxiety regarding new TESs. Businesses also need to recognize travelers’ country of residence as an important factor in TESrelated service promotion. A challenge, however, is tourism businesses' international footprint and market base. For instance, an international flight involves at least two countries, sometimes of very different levels of technological development and hence varying consumer orientations and experience with TESs. Therefore, differentiated strategies may be needed for different markets with respect to TES-related communication and education and in terms of stimulating WOM behavior.

While delivering quality TESs is a general management priority for an airline, the stronger relationship between satisfaction with TESs and overall satisfaction in the Chinese sample highlights the particular importance of this among Chinese travelers. Airlines should collect information on the most valued and used TESs by Chinese and further tailor services to market needs (e.g., providing instructions in Chinese language and in person assistance). However, the weaker relationship between overall satisfaction and future behavioral intention among Chinese requires airlines to make extra effort to entice Chinese travelers and to encourage their favorable behavior. This may be achieved through proactive customer relationship 
management and offering tangible and value added incentives, such as extra mileage points and pre-selection of service features that do not incur significant costs to airlines.

\section{Conclusions, Limitations, and Future Research}

This study clarifies TR's role in the evaluation of and satisfaction with travel technologies, and suggests TR and country of residence as factors tourism businesses must consider in formulating technology-related strategies. The study has several limitations. Respondents' evaluation of TESs relied on their most recent trip experience. However, frequent travelers may base service evaluation and future behavioral intention on experiences accumulated over time. Future research can consider a comparative study between repeat and new customers. This study reveals differences among travelers from three countries in the way satisfaction influences future behaviors - a result this study attributes to the varying cultural environments within which TES consumption takes place. However, other reasons may explain the varying strength of relationships between constructs in the conceptual model, which warrants further investigation. In addition, while this study constrained its scope to the investigation of TR's moderating effects on only relationships in the linear model illustrated in Figure 1, other factors, may also come into play which would result in alternative models. For instance, travelers' adoption and experience regarding TESs may also be shaped by role clarity, motivations, perceived enjoyment, and familiarity (Kim, Christodoulidou, and Brewer 2012; Rosenbaum and Wong 2015; Kang and Gretzel 2012a), which requires further research in order to fully disclose the role of TR in the broader satisfaction formation process. Another research avenue is to understand how the proliferation of technologies influences the way people behave in general and while traveling, as well as how the behavior differs across generations. Finally, construct measures, for instance, STES and TR scales can be further refined to better capture the essence of the constructs. 


\section{References}

Anderson, E. W., C. Fornell, and S. K. Mazvancheryl. (2004). "Customer Satisfaction and Shareholder Value." Journal of Marketing, 68 (4): 172-185.

Anderson, R. E., and S. S. Srinivasan. (2003). "E-Satisfaction and E-Loyalty: A Contingency Framework." Psychology \& Marketing, 20 (2): 123-138.

Armstrong, J. S., and T. S. Overton. (1977). "Estimating Nonresponse Bias in Mail Surveys." Journal of Marketing Research, 14 (3): 396-402.

Arnett, D. B., D. A. Laverie, and A. Meiers. (2003). "Developing Parsimonious Retailer Equity Indexes Using Partial Least Squares Analysis: A Method and Applications." Journal of Retailing, 79 (3): 161-170.

Bagozzi, R. P., and T. F. Heatherton. (1994). "A General Approach to Representing Multifaceted Personality Constructs: Application to State Self-Esteem." Structural Equation Modeling: A Multidisciplinary Journal, 1 (1): 35-67.

Beatson, A., L. V. Coote, and J. M. Rudd. (2006). "Determining Consumer Satisfaction and Commitment through Self-Service Technology and Personal Service Usage." Journal of Marketing Management, 22 (7-8): 853-882.

Bowen, D., and J. Clarke. (2002). "Reflections on Tourist Satisfaction Research: Past, Present and Future." Journal of Vacation Marketing, 8 (4): 297-308.

Buell, R. W., D. Campbell, and F. X. Frei. (2010). "Are Self-Service Customers Satisfied or Stuck?" Production and Operations Management, 19 (6): 679-697.

Chea, S., and M. M. Luo. (2008). "Post-Adoption Behaviors of E-Service Customers: The Interplay of Cognition and Emotion." International Journal of Electronic Commerce, 12 (3): 29-56.

Chen, S.-C., H.-H. Chen, and M.-F. Chen. (2009). "Determinants of Satisfaction and Continuance Intention Towards Self-Service Technologies." Industrial Management \& Data Systems, 109 (9): 1248-1263. 
Chen, S.-C., M.-L. Liu, and C.-P. Lin. (2013). "Integrating Technology Readiness into the Expectation-Confirmation Model: An Empirical Study of Mobile Services." Cyberpsychology, Behavior, and Social Networking, 16 (8): 604-612.

Chen, S. C. (2011). "Understanding the Effects of Technology Readness, Satisfaction, and Electronic Word of Mouth on Loyalty in 3C Products." Australian Journal of Business and Management Research, 1 (3).

Chin, W. W. 1998. "The Partial Least Squares Approach to Structural Equation Modelling." In Modern Methods for Business Research, edited by G. A. Marcoulides, 295-336. Mahwah, NJ: Lawrence Erlbaum Associates

Chin, W. W., and J. Dibbern. 2010. "An Introduction to a Permutation Based Procedure for Multi-Group PLS Analysis: Results of Tests of Differences on Simulated Data and a Cross Cultural Analysis of the Sourcing of Information System Services between Germany and the USA." In Handbook of Partial Least Squares, 171-193. Berlin, Germany: Springer.

Chu, S.-C., and S. M. Choi. (2011). "Electronic Word-of-Mouth in Social Networking Sites: A Cross-Cultural Study of the United States and China." Journal of Global Marketing, 24 (3): 263-281.

Chung, N., H. Han, and Y. Joun. (2015). "Tourists' Intention to Visit a Destination: The Role of Augmented Reality (AR) Application for a Heritage Site." Computers in Human Behavior, 50: 588-599.

Dabholkar, P. A. (1996). "Consumer Evaluations of New Technology-Based Self-Service Options: An Investigation of Alternative Models of Service Quality." International Journal of Research in Marketing, 13 (1): 29-51.

de Groot, R. (2015). "The Impact of Technology-Based Self-Service on Airline Passengers." Aeronautica, 3 (1): 1-78. 
do Valle, P. O., and G. Assaker. (Forthcoming). "Using Partial Least Squares Structural Equation Modeling in Tourism Research: A Review of Past Research and Recommendations for Future Applications." Journal of Travel Research.

Donthu, N., and B. Yoo. (1998). "Cultural Influences on Service Quality Expectations." Journal of Service Research, 1 (2): 178-186.

Duarte, P. A. O., and M. L. B. Raposo. 2010. "A PLS Model to Study Brand Preference: An Application to the Mobile Phone Market." In Handbook of Partial Least Squares, edited by V. E. Vinzi, W. W. Chin, J. Henseler and H. Wang, 449-485. Berlin, Germany: Springer.

Elliott, K., G. Meng, and M. Hall. (2012). "The Influence of Technology Readiness on the Evaluation of Self-Service Technology Attributes and Resulting Attitude toward Technology Usage." Services Marketing Quarterly, 33 (4): 311-329.

Ert, E., and A. Fleischer. (Forthcoming). "Mere Position Effect in Booking Hotels Online." Journal of Travel Research.

Falk, R. F., and N. B. Miller. (1992). A Primer for Soft Modeling. Akron, OH: University of Akron Press.

Ferreira, J. B., A. da Rocha, and J. F. da Silva. (2014). "Impacts of Technology Readiness on Emotions and Cognition in Brazil." Journal of Business Research, 67 (5): 865-873.

Fornell, C., and F. L. Bookstein. (1982). "Two Structural Equation Models: LISREL and PLS Applied to Consumer Exit-Voice Theory." Journal of Marketing Research, 19 (4): 440452.

Fornell, C., and D. F. Larcker. (1981). "Evaluating Structural Equation Models with Unobservable Variables and Measurement Error." Journal of Marketing Research, 18 (1): 39-50. 
Ganguli, S., and S. K. Roy. (2011). "Generic Technology-Based Service Quality Dimensions in Banking: Impact on Customer Satisfaction and Loyalty." International Journal of Bank Marketing, 29 (2): 168-189.

Gerbing, D. W., and J. C. Anderson. (1988). "An Updated Paradigm for Scale Development Incorporating Unidimensionality and Its Assessment." Journal of Marketing Research, 25 (2): 186-192.

Giebelhausen, M., S. G. Robinson, N. J. Sirianni, and M. K. Brady. (2014). "Touch Versus Tech: When Technology Functions as a Barrier or a Benefit to Service Encounters." Journal of Marketing, 78 (4): 113-124.

Gounaris, S., S. Dimitriadis, and V. Stathakopoulos. (2010). "An Examination of the Effects of Service Quality and Satisfaction on Customers' Behavioral Intentions in E-Shopping." Journal of Services Marketing, 24 (2): 142-156.

Gretzel, U., M. Kang, and W. Lee. (2008). "Differences in Consumer-Generated Media Adoption and Use: A Cross-National Perspective." Journal of Hospitality \& Leisure Marketing, 17 (1-2): 99-120.

Hair, J. F., W. C. Black, B. J. Babin, R. E. Anderson, and R. L. Tatham. (2006). Multivariate Data Analysis. Upper Saddle River, NJ: Pearson Prentice Hall.

Hair, J. F., G. T. M. Hult, C. Ringle, and M. Sarstedt. (2013). A Primer on Partial Least Squares Structural Equation Modeling (PLS-SEM). Thousand Oaks, CA: Sage Publications, Incorporated.

Hair, J. F., C. M. Ringle, and M. Sarstedt. (2011). "PLS-SEM: Indeed a Silver Bullet." The Journal of Marketing Theory and Practice, 19 (2): 139-152.

Henseler, J., and G. Fassott. 2010. "Testing Moderating Effects in PLS Path Models: An Illustration of Available Procedures." In Handbook of Partial Least Squares, edited by V. E. Vinzi, W. W. Chin, J. Henseler and H. Wang, 713-735. Berlin, Germany: Springer. 
Hofstede, G. H., and G. Hofstede. (2001). Culture's Consequences: Comparing Values, Behaviors, Institutions and Organizations across Nations. Thousand Oaks, California: Sage.

Im, I., S. Hong, and M. S. Kang. (2011). "An International Comparison of Technology Adoption: Testing the Utaut Model." Information \& Management, 48 (1): 1-8.

International Air Transport Association. (2011). Vision 2050. Singapore: International Air Transport Association.

Johnson, D. S., F. Bardhi, and D. T. Dunn. (2008). "Understanding How Technology Paradoxes Affect Customer Satisfaction with Self-Service Technology: The Role of Performance Ambiguity and Trust in Technology." Psychology \& Marketing, 25 (5): 416-443.

Kang, M., and U. Gretzel. (2012a). "Effects of Podcast Tours on Tourist Experiences in a National Park." Tourism Management, 33 (2): 440-455.

Kang, M., and U. Gretzel. (2012b). "Perceptions of Museum Podcast Tours: Effects of Consumer Innovativeness, Internet Familiarity and Podcasting Affinity on Performance Expectancies." Tourism Management Perspectives, 4: 155-163.

Kim, D. Y., J. Park, and A. M. Morrison. (2008). "A Model of Traveller Acceptance of Mobile Technology." International Journal of Tourism Research, 10 (5): 393-407.

Kim, J. S., N. Christodoulidou, and P. Brewer. (2012). "Impact of Individual Differences and Consumers' Readiness on Likelihood of Using Self-Service Technologies at Hospitality Settings." Journal of Hospitality \& Tourism Research, 36 (1): 85-114.

Lamsfus, C., D. Wang, A. Alzua-Sorzabal, and Z. Xiang. (2015). "Going Mobile Defining Context for on-the-Go Travelers." Journal of Travel Research, 54 (6): 691-701.

Lamsfus, C., D. Wang, A. Alzua-Sorzabal, and Z. Xiang. (Forthcoming). "Going Mobile Defining Context for on-the-Go Travelers." Journal of Travel Research. 
Lassar, W. M., C. Manolis, and S. S. Lassar. (2005). "The Relationship between Consumer Innovativeness, Personal Characteristics, and Online Banking Adoption." International Journal of Bank Marketing, 23 (2): 176-199.

Lee, F.-H., and W.-Y. Wu. (2011). "Moderating Effects of Technology Acceptance Perspectives on E-Service Quality Formation: Evidence from Airline Websites in Taiwan." Expert Systems with Applications, 38 (6): 7766-7773.

Lee, W., C. Castellanos, and H. Choi. (2012). "The Effect of Technology Readiness on Customers' Attitudes toward Self-Service Technology and Its Adoption; the Empirical Study of Us Airline Self-Service Check-in Kiosks." Journal of Travel \& Tourism Marketing, 29 (8): 731-743.

Liljander, V., F. Gillberg, J. Gummerus, and A. van Riel. (2006). "Technology Readiness and the Evaluation and Adoption of Self-Service Technologies." Journal of Retailing and Consumer Services, 13 (3): 177-191.

Lin, B.-W., and D. Berg. (2001). "Effects of Cultural Difference on Technology Transfer Projects: An Empirical Study of Taiwanese Manufacturing Companies." International Journal of Project Management, 19 (5): 287-293.

Lin, J.-S. C., and P.-L. Hsieh. (2006). "The Role of Technology Readiness in Customers' Perception and Adoption of Self-Service Technologies." International Journal of Service Industry Management, 17 (5): 497-517.

Lin, J.-S. C., and P.-L. Hsieh. (2007). "The Influence of Technology Readiness on Satisfaction and Behavioral Intentions toward Self-Service Technologies." Computers in Human Behavior, 23 (3): 1597-1615.

Lu, J.-L., J. K. Choi, and W.-C. Tseng. (2011). "Determinants of Passengers' Choice of Airline Check-in Services: A Case Study of American, Australian, Korean, and Taiwanese Passengers." Journal of Air Transport Management, 17 (4): 249-252. 
Lu, J., L. Wang, and L. A. Hayes. (2012). "How Do Technology Readiness, Platform Functionality and Trust Influence C2C User Satisfaction?" Journal of Electronic Commerce Research, 13 (1): 50-69.

Makarem, S. C., S. M. Mudambi, and J. S. Podoshen. (2009). "Satisfaction in TechnologyEnabled Service Encounters." Journal of Services Marketing, 23 (3): 134-144.

Mattila, A. S., and D. J. Mount. (2003). "The Impact of Selected Customer Characteristics and Response Time on E-Complaint Satisfaction and Return Intent." International Journal of Hospitality Management, 22 (2): 135-145.

Meng, J., K. M. Elliott, and M. C. Hall. (2009). "Technology Readiness Index (TRI): Assessing Cross-Cultural Validity." Journal of International Consumer Marketing, 22 (1): 19-31.

Meuter, M. L., A. L. Ostrom, M. J. Bitner, and R. Roundtree. (2003). "The Influence of Technology Anxiety on Consumer Use and Experiences with Self-Service Technologies." Journal of Business Research, 56 (11): 899-906.

Morgan, R. M., and S. D. Hunt. (1994). "The Commitment-Trust Theory of Relationship Marketing." Journal of Marketing, 58 (3): 20-38.

Nunnally, J. C. (1978). Psychometric Theory. New York: McCraw-Hill.

Nunnally, J. C., and I. H. Bernstein. (1994). Psychometric Theory. New York: McCraw-Hill.

Oliver, R. L. (1997). Satisfaction: A Behavioral Perspective on the Consumer. New York: McGraw Hill.

Parasuraman, A. (2000). "Technology Readiness Index (TRI) a Multiple-Item Scale to Measure Readiness to Embrace New Technologies." Journal of Service Research, 2 (4): 307-320.

Parasuraman, A., V. A. Zeithaml, and A. Malhotra. (2005). "ES-QUAL a Multiple-Item Scale for Assessing Electronic Service Quality." Journal of Service Research, 7 (3): 213-233.

Polites, G. L., C. K. Williams, E. Karahanna, and L. Seligman. (2012). "A Theoretical Framework for Consumer E-Satisfaction and Site Stickiness: An Evaluation in the 
Context of Online Hotel Reservations." Journal of Organizational Computing and Electronic Commerce, 22 (1): 1-37.

Rosenbaum, M. S., and I. A. Wong. (2015). "If You Install It, Will They Use It? Understanding Why Hospitality Customers Take "Technological Pauses” from Self-Service Technology." Journal of Business Research, 68 (9): 1862-1868.

So, K. K. F., C. King, and B. Sparks. (2014). "Customer Engagement with Tourism Brands: Scale Development and Validation." Journal of Hospitality \& Tourism Research, 38 (3): 304-329.

So, K. K. F., C. King, B. A. Sparks, and Y. Wang. (2016). "The Role of Customer Engagement in Building Consumer Loyalty to Tourism Brands." Journal of Travel Research, 55 (1): 64-78.

So, K. K. F., W. Liu, Y. Wang, and B. Sparks. 2016. "Service Expecations of Chinese Outbound Tourists." In Chinese Outbound Tourism 2.0, edited by X. R. Li, 185-198. Oakville, Canada: CRC Press.

Son, M., and K. Han. (2011). "Beyond the Technology Adoption: Technology Readiness Effects on Post-Adoption Behavior." Journal of Business Research, 64 (11): 1178-1182.

Spreng, R. A., and J.-s. Chiou. (2002). "A Cross-Cultural Assessment of the Satisfaction Formation Process." European Journal of Marketing, 36 (7/8): 829-839.

Srite, M., and E. Karahanna. (2006). "The Role of Espoused National Cultural Values in Technology Acceptance." MIS quarterly, 30 (3): 679-704.

Szymanski, D. M., and D. H. Henard. (2001). "Customer Satisfaction: A Meta-Analysis of the Empirical Evidence." Journal of the Academy of Marketing Science, 29 (1): 16-35.

Tam, J. L. M. (2011). "The Moderating Effects of Purchase Importance in Customer Satisfaction Process: An Empirical Investigation." Journal of Consumer Behaviour, 10 (4): 205-215. 
Tellis, G. J., E. Yin, and S. Bell. (2009). "Global Consumer Innovativeness: Cross-Country Differences and Demographic Commonalities." Journal of International Marketing, 17 (2): $1-22$.

Thong, J. Y., S.-J. Hong, and K. Y. Tam. (2006). "The Effects of Post-Adoption Beliefs on the Expectation-Confirmation Model for Information Technology Continuance." International Journal of Human-Computer Studies, 64 (9): 799-810.

Truong, Y. (2013). "A Cross-Country Study of Consumer Innovativeness and Technological Service Innovation." Journal of Retailing and Consumer Services, 20 (1): 130-137.

Tsang, N. K. F., M. T. Lai, and R. Law. (2010). "Measuring E-Service Quality for Online Travel Agencies." Journal of Travel \& Tourism Marketing, 27 (3): 306-323.

Tussyadiah, I. P., and D. Wang. (Forthcoming). "Tourists’ Attitudes toward Proactive Smartphone Systems." Journal of Travel Research.

Tussyadiah, I. P., and F. J. Zach. (2012). "The Role of Geo-Based Technology in Place Experiences." Annals of Tourism Research, 39 (2): 780-800.

Tuunanen, T., and H. Cassab. (2011). "Service Process Modularization: Reuse Versus Variation in Service Extensions." Journal of Service Research, 14 (3): 340-354

UNWTO. (2015). Unwto Tourism Highlights, 2015 Edition. Madrid, Spain: UNWTO.

Vinzi, V. E., L. Trinchera, and S. Amato. 2010. "PLS Path Modeling: From Foundations to Recent Developments and Open Issues for Model Assessment and Improvement." In Handbook of Partial Least Squares, edited by V. E. Vinzi, W. W. Chin, J. Henseler and H. Wang, 47-82. Berlin, Germany: Springer.

Walczuch, R., J. Lemmink, and S. Streukens. (2007). "The Effect of Service Employees' Technology Readiness on Technology Acceptance." Information \& Management, 44 (2): 206-215. 
Wang, D., S. Park, and D. R. Fesenmaier. (2012). "The Role of Smartphones in Mediating the Touristic Experience." Journal of Travel Research, 51 (4): 371-387.

Wang, D., Z. Xiang, and D. R. Fesenmaier. (2016). "Smartphone Use in Everyday Life and Travel." Journal of Travel Research, 55 (1): 52-63.

Wang, Y., K. K. F. So, and B. A. Sparks. (Forthcoming). "What Technology-Enabled Services Do Air Travelers Value? Investigating the Role of Technology Readiness." Journal of Hospitality \& Tourism Research.

Wang, Y., and B. Sparks. (2014). "Technology-Enabled Services: Importance and Role of Technology Readiness." Tourism Analysis, 19 (1): 19-33.

Westjohn, S. A., M. J. Arnold, P. Magnusson, S. Zdravkovic, and J. X. Zhou. (2009). "Technology Readiness and Usage: A Global-Identity Perspective." Journal of the Academy of Marketing Science, 37 (3): 250-265.

Xiang, Z., V. P. Magnini, and D. R. Fesenmaier. (2015). "Information Technology and Consumer Behavior in Travel and Tourism: Insights from Travel Planning Using the Internet." Journal of Retailing and Consumer Services, 22: 244-249.

Xiang, Z., D. Wang, J. T. O'Leary, and D. R. Fesenmaier. (2015). "Adapting to the Internet: Trends in Travelers’ Use of the Web for Trip Planning." Journal of Travel Research, 54 (4): 511-527.

Yoo, K.-H., and U. Gretzel. (2011). "Influence of Personality on Travel-Related ConsumerGenerated Media Creation." Computers in Human Behavior, 27 (2): 609-621.

Zeithaml, V. A., A. Parasuraman, and A. Malhotra. (2002). "Service Quality Delivery through Web Sites: A Critical Review of Extant Knowledge." Journal of the Academy of Marketing Science, 30 (4): 362-375. 
Table 1. Mean Scores for Measured Constructs.

\begin{tabular}{lccc}
\hline & \multicolumn{3}{c}{ Mean Score for Each Country Group } \\
\cline { 2 - 4 } Construct & U.S. & China & Australia \\
\hline Optimism & 5.25 & 5.54 & 4.97 \\
Innovativeness & 4.80 & 5.07 & 4.55 \\
Insecurity & 3.94 & 4.53 & 4.10 \\
Discomfort & 4.33 & 4.77 & 4.53 \\
TESQUAL & 4.72 & 4.44 & 4.51 \\
STES & 4.64 & 4.12 & 4.27 \\
OSAT & 4.97 & 4.46 & 4.65 \\
FBI & 5.04 & 4.52 & 4.70 \\
\hline
\end{tabular}

Note: TESQUAL = technology-enabled services quality; STES = satisfaction with technologyenabled services; OSAT = overall satisfaction; FBI = future behavioral intentions. 
Table 2. Results Summary for Reflective Measurement Models.

\begin{tabular}{|c|c|c|c|c|c|c|}
\hline Latent Variable & Indicators & Loadings & $\begin{array}{l}\text { Indicators } \\
\text { Reliability }\end{array}$ & D.G. rho & AVE & $\begin{array}{l}\text { Discriminant } \\
\text { Validity? }\end{array}$ \\
\hline \multirow[t]{3}{*}{ STES } & STES1 & .90 & .81 & .93 & .80 & Yes \\
\hline & STES2 & .90 & .81 & & & \\
\hline & STES3 & .89 & .79 & & & \\
\hline \multirow[t]{3}{*}{ OSAT } & OSAT1 & .87 & .76 & .92 & .79 & Yes \\
\hline & OSAT2 & .90 & .81 & & & \\
\hline & OSAT3 & .90 & .81 & & & \\
\hline \multirow[t]{3}{*}{ FBI } & FBI1 & .93 & .86 & .88 & .70 & Yes \\
\hline & FBI2 & .93 & .86 & & & \\
\hline & FBI3 & .62 & .38 & & & \\
\hline
\end{tabular}

Note: STES = satisfaction with technology-enabled services; OSAT = overall satisfaction; FBI = future behavioral intentions. 
Table 3. Significance Testing Results of the Structural Model Path Coefficients.

\begin{tabular}{lcccccc}
\hline Path & $\begin{array}{c}\text { Path } \\
\text { Coefficients }\end{array}$ & $\begin{array}{c}\text { Standard } \\
\text { Errors }\end{array}$ & $\begin{array}{c}\text { Critical } \\
\text { Ratios }\end{array}$ & p Values & $\begin{array}{c}\text { 95\% Confidence } \\
\text { Intervals }\end{array}$ & $\begin{array}{c}\text { Variance Due to } \\
\text { Path }\end{array}$ \\
\hline TESQUAL $\rightarrow$ STES & .384 & .030 & 12.62 & $* * *$ & {$[.31, .44]$} & .146 \\
STES $\rightarrow$ OSAT & .801 & .014 & 57.90 & $* * *$ & {$[.77, .83]$} & .641 \\
OSAT $\rightarrow$ FBI & .834 & .011 & 79.09 & $* * *$ & {$[.81, .86]$} & .701 \\
Controlled Variables & & & & & & \\
Age $\rightarrow$ STES & -.036 & .026 & -1.365 & NS & {$[-.09, .02]$} & \\
Gender $\rightarrow$ STES & -.035 & .022 & -1.579 & NS & {$[-.08, .00]$} & \\
Edu $\rightarrow$ STES & -.088 & .025 & -3.453 & $* * *$ & {$[-.15,-.04]$} & \\
Age $\rightarrow$ OSAT & .094 & .018 & 5.461 & $* * *$ & {$[.05, .13]$} & {$[-.03, .04]$} \\
Gender $\rightarrow$ OSAT & .008 & .017 & .427 & NS & {$[-.04, .04]$} & \\
Edu $\rightarrow$ OSAT & .004 & .017 & .106 & NS & {$[.04, .11]$} \\
Age $\rightarrow$ FBI & .069 & .017 & 4.101 & $* * *$ & NS \\
Gender $\rightarrow$ FBI & .004 & .014 & .253 & NS & {$[-.03, .03]$} \\
Edu $\rightarrow$ FBI & .024 & .013 & 1.842 & NS & {$[-.00,05]$} &
\end{tabular}

Note: TESQUAL = technology-enabled services quality; STES = satisfaction with technology-enabled services; OSAT = overall satisfaction; FBI = future behavioral intentions; Edu = highest education achieved; ${ }^{* * *} p<.01$; NS = not significant. 
Table 4. Results of Moderating Effect of Optimism.

\begin{tabular}{lccccccc}
\hline & \multicolumn{2}{c}{ Group 1: Low OPT } & & \multicolumn{2}{c}{ Group 2: High OPT } & \multicolumn{2}{c}{ Group 1 vs. Group 2 } \\
\cline { 2 - 5 } & $\begin{array}{c}\text { Path } \\
\text { Coefficient }\end{array}$ & $\begin{array}{c}\text { Critical } \\
\text { Ratio }\end{array}$ & $\begin{array}{c}\text { Path } \\
\text { Coefficient }\end{array}$ & $\begin{array}{c}\text { Critical } \\
\text { Ratio }\end{array}$ & $\begin{array}{c}\text { Path } \\
\text { Difference }\end{array}$ & $p$-Value \\
\hline TESQUAL $\rightarrow$ STES & .31 & $7.70^{* * *}$ & .40 & $10.59 * * *$ & .08 & .18 \\
STES $\rightarrow$ OSAT & .69 & $22.49^{* * *}$ & .85 & $69.94 * * *$ & .16 & $* * *$ \\
OSAT $\rightarrow$ FBI & .78 & $31.37 * * *$ & .85 & $74.02 * * *$ & .07 & $* * *$ \\
\hline
\end{tabular}

Note: $\mathrm{OPT}=$ optimism; TESQUAL = technology-enabled services quality; STES = satisfaction with technology-enabled services; OSAT = overall satisfaction; FBI = future behavioral intentions; path differences were generated from permutation; ${ }^{* * *} p<.01$. 
Table 5. Results of Moderating Effect of Innovativeness.

\begin{tabular}{lcccccc}
\hline & \multicolumn{2}{c}{ Group 1: Low INN } & & \multicolumn{2}{c}{ Group 2: High INN } & \multicolumn{2}{c}{ Group 1 vs. Group 2 } \\
\cline { 2 - 5 } & $\begin{array}{c}\text { Path } \\
\text { Coefficient }\end{array}$ & $\begin{array}{c}\text { Critical } \\
\text { Ratio }\end{array}$ & $\begin{array}{c}\text { Path } \\
\text { Coefficient }\end{array}$ & $\begin{array}{c}\text { Critical } \\
\text { Ratio }\end{array}$ & $\begin{array}{c}\text { Path } \\
\text { Difference }\end{array}$ & $p$-Value \\
\hline TESQUAL $\rightarrow$ STES & .34 & $7.58^{* * *}$ & .40 & $9.73^{* * *}$ & .06 & .32 \\
STES $\rightarrow$ OSAT & .71 & $25.81^{* * *}$ & .85 & $57.04^{* * *}$ & .14 & $* * *$ \\
OSAT $\rightarrow$ FBI & .79 & $38.60^{* * *}$ & .86 & $73.15^{* * *}$ & .07 & $* * *$ \\
\hline
\end{tabular}

Note: INN = innovativeness; TESQUAL = technology-enabled services quality; STES = satisfaction with technology-enabled services; OSAT = overall satisfaction; FBI = future behavioral intentions; path differences were generated from permutation; $* * * p<.01$. 
Table 6. PLS Multigroup Analysis for Three Country Groups.

\begin{tabular}{|c|c|c|c|c|c|c|c|c|c|c|c|c|}
\hline \multirow[b]{2}{*}{ Paths } & \multicolumn{2}{|c|}{ Group 1: U.S. } & \multicolumn{2}{|c|}{ Group 2: China } & \multicolumn{2}{|c|}{ Group 3: Australia } & \multicolumn{2}{|c|}{ Group 1 vs. Group 2} & \multicolumn{2}{|c|}{ Group 1 vs. Group 3} & \multicolumn{2}{|c|}{ Group 2 vs. Group 3} \\
\hline & $\begin{array}{c}\text { Path } \\
\text { Coefficients }\end{array}$ & $\begin{array}{l}\text { Critical } \\
\text { Ratios }\end{array}$ & $\begin{array}{c}\text { Path } \\
\text { Coefficients }\end{array}$ & $\begin{array}{l}\text { Critical } \\
\text { Ratios }\end{array}$ & $\begin{array}{c}\text { Path } \\
\text { Coefficients }\end{array}$ & $\begin{array}{c}\text { Critical } \\
\text { Ratios }\end{array}$ & $\begin{array}{c}\text { Path } \\
\text { Difference }\end{array}$ & $p$-Value & $\begin{array}{c}\text { Path } \\
\text { Difference }\end{array}$ & $p$-Value & $\begin{array}{c}\text { Path } \\
\text { Difference }\end{array}$ & p Value \\
\hline TESQUAL $\rightarrow$ STES & .36 & $8.34^{* * *}$ & .39 & $7.91^{* * *}$ & .35 & $4.85^{* * *}$ & .03 & .64 & .00 & .92 & .04 & .70 \\
\hline STES $\rightarrow$ OSAT & .79 & $39.12 * * *$ & .84 & $48.59 * * *$ & .77 & $21.03 * * *$ & .05 & $* *$ & .00 & .97 & .06 & .16 \\
\hline OSAT $\rightarrow$ FBI & .86 & $60.18^{* * *}$ & .78 & $34.10 * * *$ & .83 & $35.29 * * *$ & .08 & $* * *$ & .04 & .21 & .04 & .17 \\
\hline
\end{tabular}

Note: TESQUAL = technology-enabled services quality; STES = satisfaction with technology-enabled services; OSAT = overall satisfaction; FBI = future behavioral intentions; path differences were generated from permutation; ${ }^{* *} p<.05:{ }^{* *} p<.01$ 


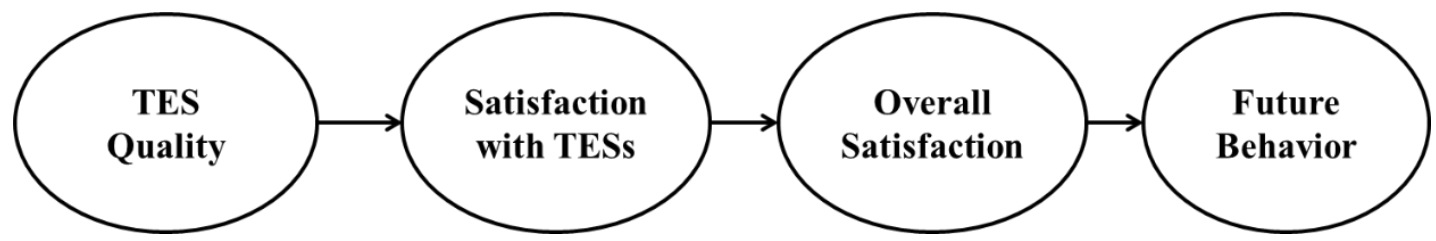

Figure 1. Framework of tourism satisfaction. 


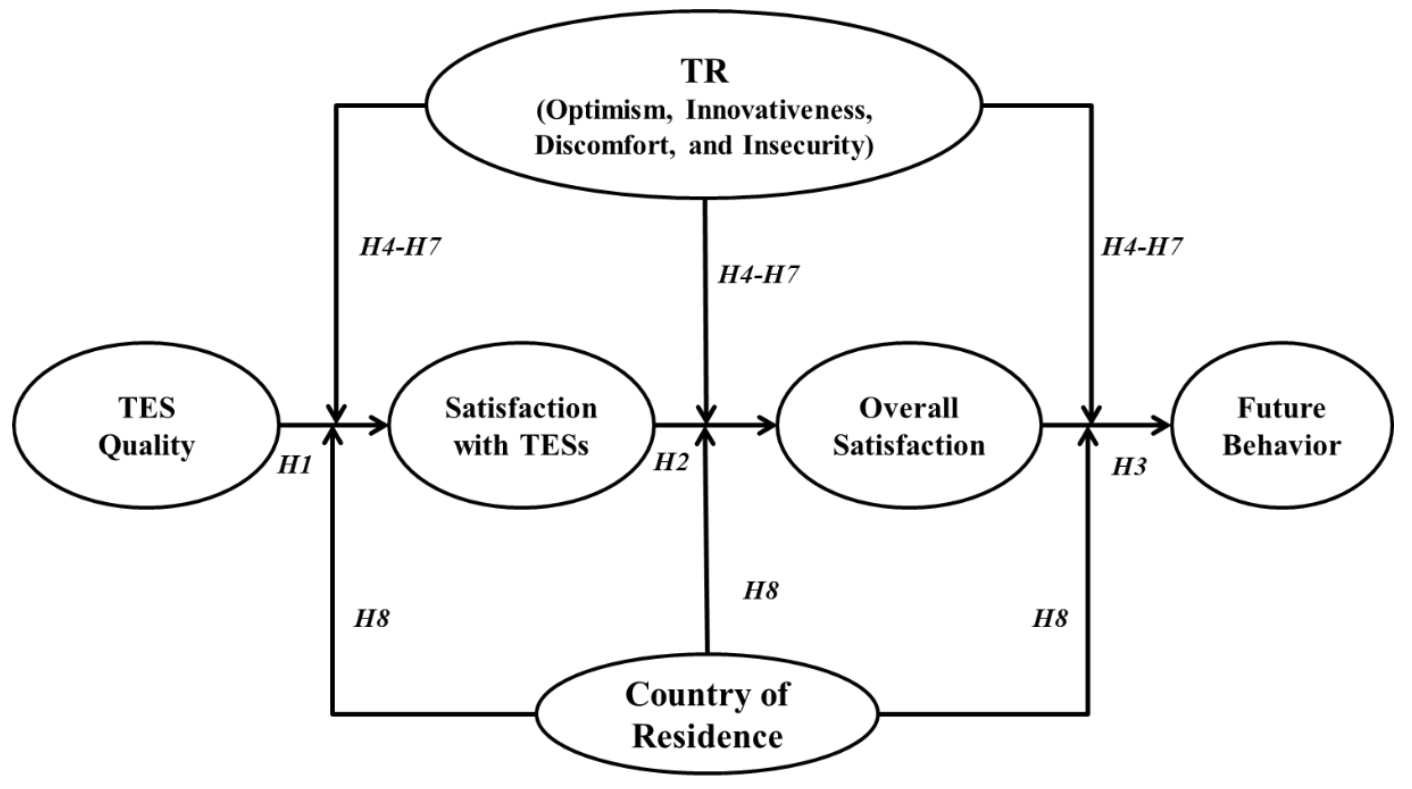

Figure 2. The conceptual framework 